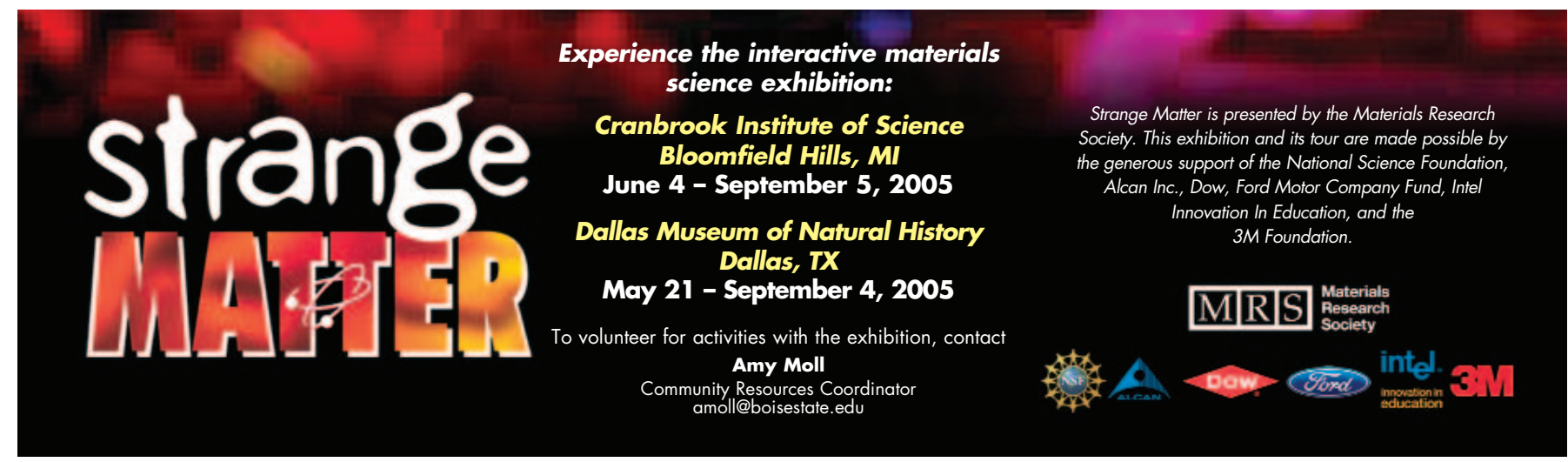

\title{
Growing Up with Popular Culture
}

When I was just old enough to be able to turn on a television, I was among a vanguard-the first generation for whom TV was "always there." Turning the thing on was a little more challenging than it is for today's toddlers. There was no remote control, and the combined on/off switch and volume control was very stiff for little fingers, but any time I turned it on (if it was not during the daytime hours when the two channels available in the United Kingdom only broadcast a test pattern), then I could rely on seeing a "Western." Cowboys and Indians: the great staple of British popular culture in the 1950s and 1960s. Every night of the week, a different six-gun hero took to the screen, and my dreams were filled with black-and-white Western landscapes, a clear delineation between good and evil, and a ride along with Hopalong Cassidy, the Lone Ranger, Roy Rogers, Wyatt Earp, or even Lassie or Rin Tin Tin. The best gift ever was a pair of cap guns with a two-holster gun belt, a cowboy hat (not quite 10 gallons, I imagine) and a Western-style waistcoat with a sheriff's badge pinned to it. With all that on, riding my bike through the streets, I was truly home on the range, out there in the southwestern suburbs of London. When I grew up, I was going to be a cowboy.

As the years went by, the horse operas became ever so slightly more sophisticated as we progressed from shows like Gunsmoke, Wagon Train, and Laramie to Bonanza and The Virginian. The smoke signals were clear, though: The days of the Western were numbered. Down from seven nights a week, eventually only to one, in the late 1960s and 1970s, they were replaced (along with that first TV set) by another classic venue for the battle between good and evil: Cops and Robbers. At some point, the television schedule sustained as many as four different cop shows produced in the United Kingdom, and several more from the U.S. networks. As with the Westerns, these shows grew in sophistication (also violence level) and migrated from the early-evening "family viewing" time slots into what we now call "prime time."

\section{"After decades of being just some kind of geek, my line of work now makes me cool."}

My own life was changing, of course, with more homework to do and less time available for TV, despite a later bedtime, but once in a while my parents would have some time to sit and watch the thing at the same time that I did. My father was a detective in the London police force, and he watched those cop and robber shows with a professional eye. Most of the time he refrained from comment, but every now and then he would give a little lecture on how clever it was to condense a whole investigation into a one-hour show, but how much realism was lost in the process. He would start explaining what real police work was like, but his audience had been trained by $\mathrm{TV}$ - a short attention span and a strong preference for the spectacular over the more mundane aspects of real life. Despite the dreams of my contemporaries, I was pretty sure that when I grew up I was not going to be a policeman.

Fast-forward three or four decades, during which I have watched TV only sporadically. Much has changed, but a surprising amount has stayed the same. Despite the overload of radically misnomered "reality TV" shows, the cops and robbers are still holding their own, and in an amazing development, scientists are the heroes of the age. A show that focuses on a group of forensics officers in Las Vegas has become so popular that it has spawned two spin-offs, based in Miami and New York: three nights a week of science-based sleuthing; good versus evil, determined in the cold precision of the laboratory. These modern heroes use the same tools that are found in my own laboratory- "Hey, kids, come and take a look at this...."

Enrollments in university forensic science programs and related fields are suddenly exploding. After decades of being just some kind of geek, my line of work now makes me cool. At last, what I want to be when I grow up is already me. A little too late, if you ask me, but all you younger lab-rats out there should consider some hairstyle and wardrobe adjustments to take the greatest possible advantage of your new place in the popular culture. Think about accessorizing your outfit with a little labware, perhaps.

Just one thing-be careful about criticizing these shows. Sure, a real lab does not work that way: Vacuum that is instantly established: hah!... SEMs that display the critical area of interest as soon as they are turned on: right!... instruments that require no alignment or calibration: you wish!... chemical compositions that are unique to a particular product: oh sure!... and all those cool specialty databases with their graphically enhanced search engines: I don't think so!... One day you reach a certain age, and when you wake up in the morning and look blearily into the bathroom mirror, you find your father or mother looking back at you. When that happened to me, the morning after I watched CSI: Miami for the first time, my father seemed to be saying "Real police work, of course, is nothing like that ...."

Alex KING 